RESENDE, F.V.; OLIVEIRA, P.S.R. de; SOUZA, R.J. de. Crescimento, produção e absorção de nitrogênio do alho proveniente de cultura de tecidos, cultivado com doses elevadas de nitrogênio. Horticultura Brasileira, Brasília, v. 18, n. 1, p. 31-36, março 2.000.

\title{
Crescimento, produção e absorção de nitrogênio do alho proveniente de cultura de tecidos, cultivado com doses elevadas de nitrogênio.
}

\author{
Francisco V. Resende ${ }^{1}$; Paulo Sérgio R. de Oliveira ${ }^{1}$; Rovilson José de Souza ${ }^{2}$ \\ ${ }^{1}$ UNIMAR - Faculdade de Ciências Agrárias, C. Postal 554, 17.525-902 Marília - SP; ${ }^{2}$ UFLA, C. Postal 37, 37.200-000 Lavras - MG.
}

\section{RESUMO}

Este trabalho foi realizado em Marília (SP), com o objetivo de estudar o crescimento, produção, absorção de $\mathrm{N}$ e as correlações entre estas características, no alho obtido por cultura de tecidos, cultivado em doses elevadas de N. Foram utilizadas cinco doses de N: 0, 80, 140,200 e 250 kg/ha, adotando-se delineamento experimental de blocos casualizados com quatro repetições. O número de folhas/planta e a razão bulbar aumentaram proporcionalmente à elevação da dose de $\mathrm{N}$ no solo. A altura da planta e o acúmulo de matéria seca, por outro lado, demostraram uma resposta quadrática, aumentando até as doses de 180 e 164 kg/ha de $\mathrm{N}$, respectivamente. A acumulação de $\mathrm{N}$ também seguiu o comportamento quadrático para parte aérea e bulbo, entretanto, somente o bulbo apresentou um ponto máximo de acúmulo na dose de $182 \mathrm{~kg} / \mathrm{ha}$. Para produção total de bulbos, verificou-se um comportamento quadrático, aumentando até a dose de $234 \mathrm{~kg} / \mathrm{ha}$ de $\mathrm{N}$. A produção comercial foi afetada negativamente pelos níveis de $\mathrm{N}$ mais elevados, apresentando uma curva de resposta quadrática. A produção comercial máxima estimada (18,74 t/ha) foi verificada para uma dose de $194,4 \mathrm{~kg}$ de $\mathrm{N}$ por hectare. Os níveis de resposta ao $\mathrm{N}$ do alho proveniente da cultura de tecido mostraram-se superiores ao do alho multiplicado de forma convencional. Foram verificadas correlações altamente significativas entre a quantidade de $\mathrm{N}$ extraída e as características de produção da planta.
ABSTRACT

Growth, yield and nitrogen uptake in garlic obtained by tissue culture, cultivated under high nitrogen levels.

This work was accomplished in Marília county, State of São Paulo - Brazil, with the objective of studying the growth, production, $\mathrm{N}$ uptake and correlations between these characteristics, on tissue culture garlic cultivated under high nitrogen levels. Five levels of N were used: $0,80,140,200$ and $250 \mathrm{~kg} / \mathrm{ha}$ in a randomised block design with four replications. The number of leaves per plant and the bulbing ratio increased under high $\mathrm{N}$ levels in the soil. The plant height and dry matter accumulation showed a quadratic response, reaching maximum values at $\mathrm{N}$ levels of 180 and $164 \mathrm{~kg} / \mathrm{ha}$, respectively. The $\mathrm{N}$-accumulation on leaves and bulbs also followed the quadratic behaviour, although only the bulb showed a maximum value of $\mathrm{N}$-accumulation under the level of $182 \mathrm{~kg} / \mathrm{ha}$. For total yield, a quadratic effect was observed, increasing up to $234 \mathrm{~kg} / \mathrm{ha}$ of $\mathrm{N}$. The commercial yield was negatively affected by the high $\mathrm{N}$ levels, showing a quadratic effect. The maximum estimated commercial yield (18.74 t/ha) was obtained under $194.4 \mathrm{~kg} / \mathrm{ha}$ of N. Garlic plants originated from tissue culture had better response to higher $\mathrm{N}$ levels than those whose bulbs were multiplied in the field. Highly significant correlations were observed between $\mathrm{N}$-accumulation and the plant production components.

Palavras-chave: Allium sativum L., multiplicação "in vitro", adubação nitrogenada.

(Aceito para publicação em 11 de fevereiro de 2.000)

$\mathrm{T}$ em sido demonstrado por meio de resultados experimentais que a utilização da cultura de tecidos em alho, com intuito de eliminar viroses, tem resultado em materiais com crescimento e produção significativamente superiores aos multiplicados pela via convencional (Resende, 1997). Esse comportamento sugere que as exigências nutricionais destas plantas serão alteradas pela ausência de viroses nos materiais limpos de vírus. Portanto, para viabilizar a utilização do alho oriundo de cultura de tecidos em escala comercial, muitas questões relacionadas à nutrição e adubação precisam ser esclarecidas, para que o produtor possa explorar todo potencial produtivo proporcionado pela cultura de tecidos.

Neste contexto, o $\mathrm{N}$ merece atenção especial por ser um dos nutrientes mais exigidos pela cultura do alho e pela sua influência na severidade de várias doenças, destacando-se nesse caso as viroses. Sabe-se que em alguns situações, o vírus pode direcionar para sua reprodução até $75 \%$ do conteúdo de proteínas de uma célula, além de afetar o conteúdo de outros compostos ricos em $\mathrm{N}$ como os açúcares e a clorofila (Gibbs \& Harrison, 1979).

Verifica-se, na literatura internacional, resposta a níveis elevados de $\mathrm{N}$ pelo alho, podendo chegar a $360 \mathrm{~kg} / \mathrm{ha}$ (Maksoud et al., 1984). No Brasil, entretanto, o alho responde a níveis bem mais modestos, atingindo no máximo $100 \mathrm{~kg} /$ ha (Menezes Sobrinho et al., 1974). No caso de alho proveniente de cultura de tecidos comprovou-se a capacidade de resposta ao $\mathrm{N}$ em níveis significativamente superiores aos materiais multiplicados de forma convencional. (Barni
\& Garcia, 1994; Resende, 1997), verificaram que o alho proveniente de cultura de tecidos respondeu efetivamente às adubações mais pesadas com $\mathrm{N}$ que as plantas da mesma cultivar multiplicadas de forma convencional.

Partindo das observações desses autores, procurou-se neste trabalho identificar a real capacidade de resposta ao $\mathrm{N}$ por plantas de alho provenientes de cultura de tecidos, avaliando o comportamento das mesmas quando cultivadas em níveis elevados de $\mathrm{N}$, bem como correlacionar, nestas condições, a quantidade de $\mathrm{N}$ absorvida pela planta com seu crescimento e produção.

\section{MATERIAL E MÉTODOS}

Este trabalho foi realizado na Universidade de Marília (UNIMAR), em 


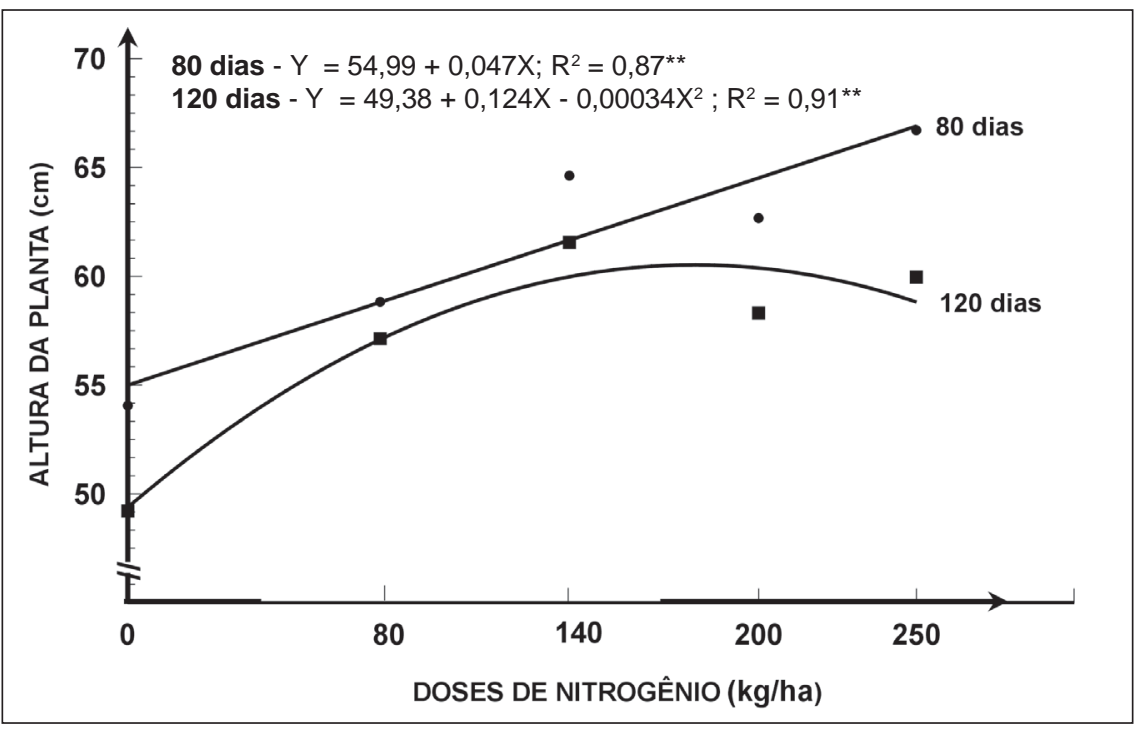

Figura 1. Altura aos 80 e 120 dias após o plantio, de plantas de alho provenientes de cultura de tecidos em função das doses de nitrogênio aplicadas. Marília (SP), UNIMAR, 1997.

Marília (SP), utilizando material propagativo da cultivar Gigante Roxão multiplicado através de cultura de tecidos, no Laboratório de Biotecnologia da Universidade Federal de Lavras (UFLA). As plantas utilizadas neste trabalho foram multiplicadas durante dois anos em campos isolados de lavouras comerciais em Lavras (MG). Em função da ausência de caracterização das viroses que ocorrem no alho no Brasil e, consequentemente, inexistência de anti-soros específicos (Dusi, 1995), não foram realizados testes de indexação para presença de viroses nas plantas estudadas.

A cultivar Gigante Roxão pertence ao grupo dos alhos semi-nobres (ciclo médio), apresenta bulbos com película de coloração arroxeada, pequena incidência de bulbilhos "palitos", boa resistência ao pseudo-perfilhamento e adaptação às condições de plantio do Sudeste e Centro Oeste do país dispensando a necessidade de vernalização (EMBRAPA, 1984).

O experimento foi conduzido na Fazenda Experimental da UNIMAR no período de 16/04/1997 a 23/09/1997 em um solo classificado como Podzólico Vermelho Amarelo de transição abrupta, com as seguintes características químicas: $\mathrm{pH}$ em $\mathrm{CaCl}_{2}$ : 6,2; matéria orgânica: $20,8 \mathrm{~g} \mathrm{dm}^{-3}$; P: $121 \mathrm{mg} \mathrm{dm}^{-3}$; $\mathrm{K}$ : 5,1 $\mathrm{mmol}_{\mathrm{c}} \mathrm{dm}^{-3}$; $\mathrm{Ca}: 43 \mathrm{mmol} \mathrm{dm}^{-3} ; \mathrm{Mg}$ : $26 \mathrm{mmol}_{\mathrm{c}} \mathrm{dm}^{-3}$; V: $82 \%$.

As adubações de plantio basearamse em recomendações para o Estado de
São Paulo, seguindo informações do Boletim 100 (Raij et al., 1996) para o alho comum, constando de $120 \mathrm{~kg} / \mathrm{ha}$ de $\mathrm{P}_{2} \mathrm{O}_{5}, 40 \mathrm{~kg} / \mathrm{ha}$ de $\mathrm{K}_{2} \mathrm{O}, 10 \mathrm{~kg} / \mathrm{ha}$ de ácido bórico e sulfato de zinco e $50 \mathrm{~kg} / \mathrm{ha}$ de sulfato de magnésio.

Utilizou-se o delineamento experimental de blocos casualizados, com quatro repetições. As parcelas foram dimensionadas com 1,00 m de largura por 2,00 $\mathrm{m}$ de comprimento, constando de 5 fileiras de 20 plantas, totalizando 100 plantas/parcela. Como área útil, foram consideradas as três fileiras centrais, excluindo-se as duas últimas plantas de cada extremidade da parcela. $\mathrm{O}$ espaçamento utilizado para o plantio foi de $0,10 \mathrm{~m}$ entre plantas e 0,20 m entre fileiras.

Os tratamentos constituíram-se de cinco doses de nitrogênio: $0,80,140$, 200 e $250 \mathrm{~kg} / \mathrm{ha}$, utilizando uréia como fonte, parceladas em três aplicações: no plantio, aos 45 e 70 dias após o plantio.

Após o plantio foi colocado sobre os canteiros, uma camada de $5 \mathrm{~cm}$ de casca de arroz (cobertura morta) com a função de manter a umidade e a temperatura do solo adequadas à emergência das plântulas. O controle das plantas daninhas foi realizado com aplicações em pós-emergência, utilizando os herbicidas Fluazifop-butyl e Linuron nas dosagens recomendadas para cada produto e capinas manuais quando necessário. Foram realizadas pulverizações semanais com produtos à base de Mancozeb, Iprodione,
Tebuconazole, Vamidothion e Parathionmetyl visando o controle preventivo de pragas e doenças.

Foram avaliados aos 80 e 120 dias após o plantio, a altura da planta, o número médio de folhas/planta e a razão bulbar que mede a relação entre o diâmetro do pseudocaule e diâmetro do bulbo em formação, fornecendo uma estimativa da taxa de bulbificação da planta (Mann, 1952). Aos 120 dias foram coletadas amostras de 3 plantas/ parcela, secadas em estufa a $\pm 70^{\circ} \mathrm{C}$ até peso constante para obtenção da produção de matéria seca. A quantificação do $\mathrm{N}$ na planta foi realizada no Laboratório de Solos e Adubação da Universidade de Marília pelo método semi-microkjeldahl com digestão ácida quente.

As plantas atingiram o ponto de colheita aos 160 dias após o plantio. Os bulbos foram curados em local seco e ventilado durante 50 dias, sendo então classificados por tamanho e pesados para obtenção das produções total e comercial. Para produção comercial foram considerados apenas bulbos com diâmetro superior a $35 \mathrm{~mm}$, intactos, livres de sintomas de ataque de pragas e doenças e em perfeito estado de conservação.

Os dados obtidos foram submetidos aos testes de Lilliefors e Barttlet para verificar, respectivamente, o ajuste aos critérios de normalidade e homogeneidade exigidos para a análise de variância (Little \& Hills, 1978). Os valores médios das características estudadas foram ajustados à curva de resposta (regressão) em função das doses de N (Gomes, 1990).

\section{RESULTADOS E DISCUSSÃO}

As doses de $\mathrm{N}$ influenciaram significativamente $(p<0,01)$ a altura da planta e o número médio de folhas/planta aos 80 e 120 dias após o plantio. Os resultados para a altura das plantas indicaram aos 80 dias, uma tendência linear de resposta ao aumento das doses de N, enquanto aos 120 dias prevaleceu um comportamento tipicamente quadrático (Figura 1). O número médio de folhas apresentou uma relação linear, aumentando proporcionalmente ao incremento das doses de $\mathrm{N}$ aos 80 e 120 dias (Figura 2). A altura da planta alcançou, aos 120 
dias, um valor máximo estimado de 60,7 $\mathrm{cm}$ para a dose de $182,3 \mathrm{~kg} / \mathrm{ha}$. Para o número médio de folhas/planta o valor máximo ocorreu fora do intervalo de doses estudados. Uma vez que o desenvolvimento vegetativo do alho intensifica-se no período entre 60 e 120 dias após o plantio (Silva et al., 1970), a resposta linear apresentada aos 80 dias torna-se coerente, pois nesse período as plantas encontram-se em pleno crescimento. Da mesma forma, o comportamento quadrático aos 120 dias, explicase pela coincidência com o início da senescência da parte aérea.

$\mathrm{O}$ efeito positivo do $\mathrm{N}$ no crescimento e no aumento da massa foliar do alho tem sido observado tanto em plantas multiplicadas de forma convencional (Souza, 1990; Resende, 1992), quanto provenientes de cultura de tecidos (Resende, 1997).

As produções de matéria seca das folhas $(\mathrm{p}<0,05)$, bulbo $(\mathrm{p}<0,01)$ e total $(\mathrm{p}<0,01)$, aos 120 dias após o plantio, mostraram-se significativamente influenciadas pelo aumento das doses de N, apresentando para todas estas características, com exceção da matéria seca total que mostrou comportamento linear, relação quadrática com o aumento de $\mathrm{N}$ no solo (Figura 3). As respostas significativas obtidas nesta época foram sustentadas pelo trabalho de Silva et al., (1970). Segundo estes autores, entre 90 e 135 dias a bulbificação do alho é intensificada resultando no aumento da demanda de nutrientes (principalmente $\mathrm{N}$ e K). Durante este período a planta absorve $49 \%$ do $\mathrm{N}$ total e os bulbos passam a responder por mais de $50 \%$ da matéria seca total da planta (Zink, 1963).

Analisando-se as curvas de ajuste (Figura 3), observa-se que a quantidade de matéria seca cresceu para parte aérea até a dose de $183,3 \mathrm{~kg} / \mathrm{ha}(8,96 \mathrm{~g} / \mathrm{plan}$ ta), para o bulbo até $168 \mathrm{~kg} / \mathrm{ha}(13,25 \mathrm{~g} /$ planta) e para o total até $166,6 \mathrm{~kg} / \mathrm{ha}$ $(23,50 \mathrm{~g} /$ planta) de nitrogênio. Estes resultados complementaram as observações de Resende (1997), que verificou aumentos lineares na matéria seca, num intervalo de doses de 0 e $140 \mathrm{~kg} / \mathrm{ha}$ de $\mathrm{N}$, em folhas, bulbos e raízes de plantas multiplicadas através de cultura de tecidos. Em plantas multiplicadas pela via convencional, segundo este autor, os pon-

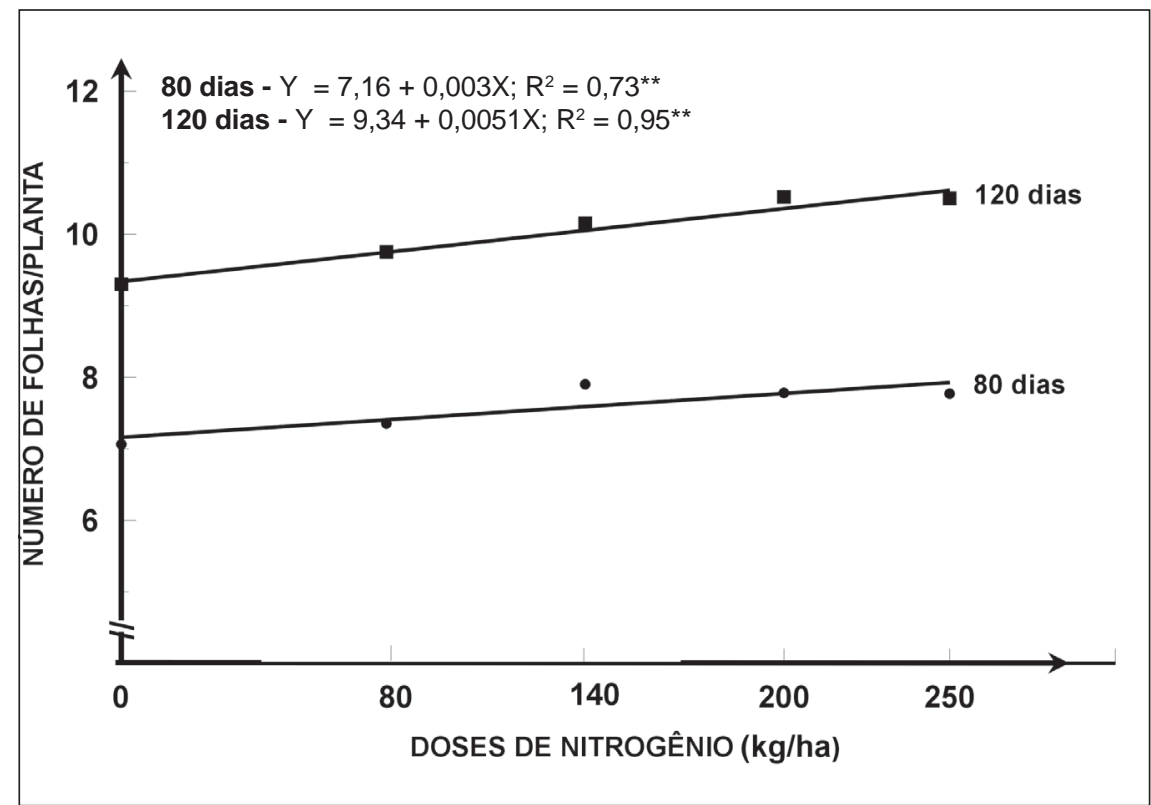

Figura 2. Número médio de folhas por planta aos 80 e 120 dias após o plantio, de plantas de alho provenientes de cultura de tecidos em função das doses de nitrogênio aplicadas. Marília (SP), UNIMAR, 1997.

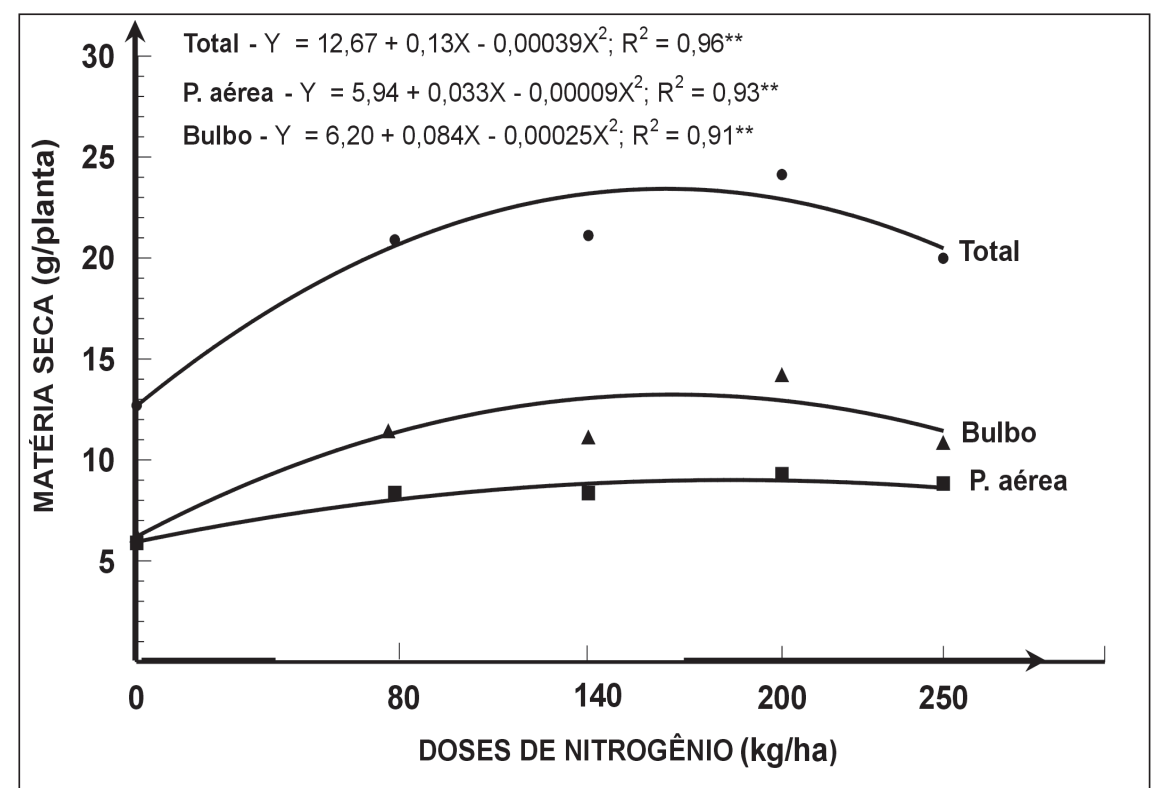

Figura 3. Matéria seca das folhas, bulbo e total aos 120 dias após o plantio, de plantas de alho provenientes de cultura de tecidos em função das doses de nitrogênio aplicadas. Marília (SP), UNIMAR, 1997.

tos máximos de produção de matéria seca foram obtidas nas doses de 105 e $102 \mathrm{~kg}$ / ha, respectivamente, na parte aérea e total, e $118 \mathrm{~kg} / \mathrm{ha}$ para o bulbo aos 110 dias após o plantio.

A razão bulbar foi afetada pelo $\mathrm{N}$ apenas aos 120 dias $(\mathrm{p}=0,06)$, traduzindo-se numa relação linear positiva com o incremento das doses de N. Como o aumento da razão bulbar indica atraso na bulbificação, este resultado mostra que a formação do bulbo foi limitada pela elevação das doses de N (Figura 4). Esta relação linear expressa, de maneira geral, a mesma tendência observada em outros trabalhos com alho de cultura de tecidos (Resende, 1997) e convencional (Santos et al.,1984). Aos 80 dias, o aumento das aplicações de $\mathrm{N}$ não interferiu na razão bulbar. Nesta 


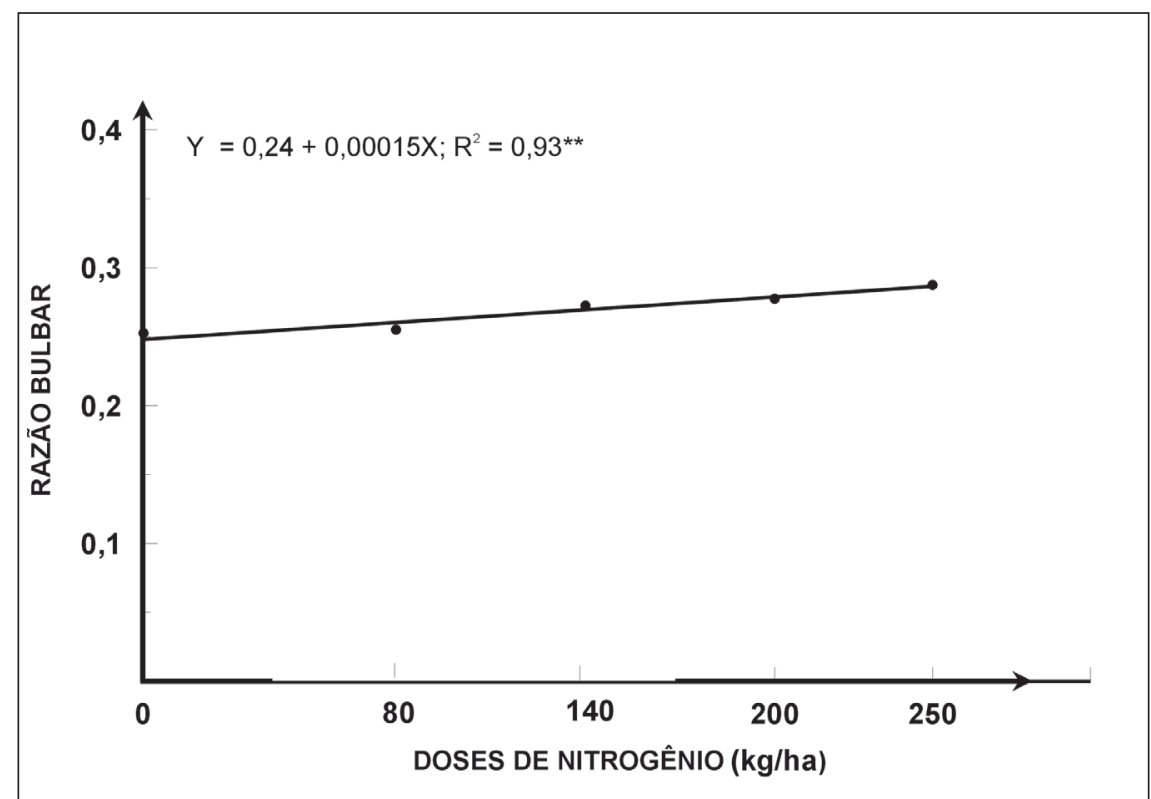

Figura 4. Razão bulbar aos 120 dias após o plantio, de plantas de alho provenientes de cultura de tecidos em função das doses de nitrogênio aplicadas. Marília (SP), UNIMAR, 1997.

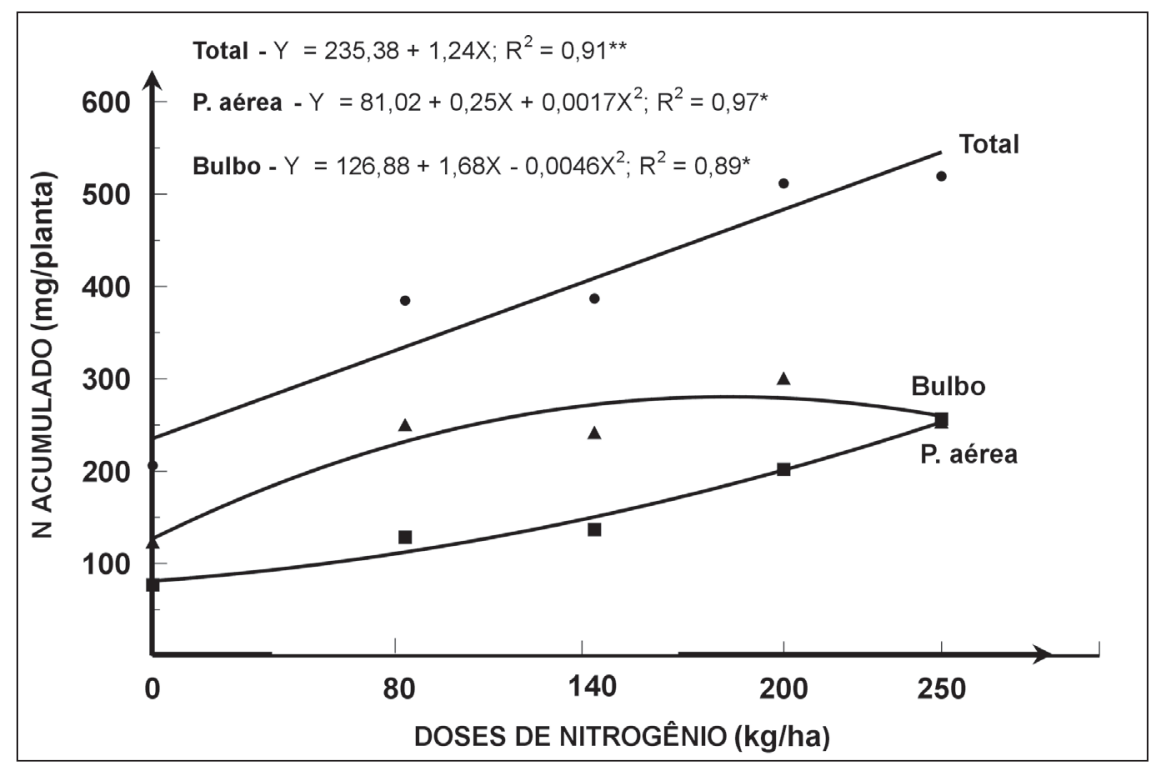

Figura 5. Quantidade de nitrogênio absorvido pela parte aérea, bulbo e total aos 120 dias após o plantio, de plantas de alho provenientes de cultura de tecidos em função das doses de nitrogênio aplicadas. Marília (SP), UNIMAR, 1997.

época, a formação do bulbo encontrase ainda pouco evidente e, portanto, a exigência nutricional é mínima nesta parte da planta.

Segundo Mann (1952), quando a razão bulbar reduz-se a níveis inferiores a 0,5, o bulbo encontra-se completamente formado e para valores menores que 0,2 encontra-se em fase final de maturação. Nota-se que com estas pressuposições, mesmo estando completamente formados aos 120 dias após o plantio, a elevação das doses de $\mathrm{N}$ provocou, nesta de N. Embora a quantidade acumulada de $\mathrm{N}$ em todas as partes, à exceção do acúmulo total que apresentou resposta linear, tendeu para um comportamento quadrático em relação às doses deste nutriente (Figura 5), apenas para o bulbo detectou-se um ponto de máximo acúmulo de $\mathrm{N}$, que segundo a equação ajustada, foi igual a $280,27 \mathrm{mg} /$ planta na dose de $182,60 \mathrm{~kg} / \mathrm{ha}$ de $\mathrm{N}$. O N total acumulado atingiu o valor calculado de $545,38 \mathrm{mg} /$ planta na dose máxima utilizada (250 kg/ha). Assemelhando-se aos resultados de Resende (1997), que observou um acúmulo crescente de $\mathrm{N}$ até $228 \mathrm{mg} /$ planta para dose máxima aplicada (140 kg/ha) deste nutriente em plantas de alho de cultura de tecidos (as plantas convencionais acumularam o máximo de 132,2 mg/planta com $107 \mathrm{~kg} / \mathrm{ha}$ de $\mathrm{N}$ ), verificou-se também que a absorção de $\mathrm{N}$ aumentou de forma proporcional à disponibilidade deste nutriente no solo, ou seja, até a dose de $250 \mathrm{~kg} / \mathrm{ha}$.

A absorção de nutrientes pelo alho acompanha o crescimento das folhas, das raízes e principalmente do bulbo (Zink, 1963; Silva et al., 1970). Este comportamento pode ser notado, de maneira geral, pela similaridade de resposta ao $\mathrm{N}$ entre as características de crescimento da planta e a quantidade de nitrogênio absorvido e corroborado pelas correlações positivas e altamente significativas $(\mathrm{p}<0,01)$ entre a acumulação de $\mathrm{N}$ e a produção de matéria seca e peso dos bulbos; fato constatado também entre o $\mathrm{N}$ total absorvido e as produções total e comercial (Tabela 1).

Aos 120 dias após o plantio, não foram observadas correlações significativas entre a altura da planta e a matéria seca das folhas com a quantidade de $\mathrm{N}$ extraída por estas partes (Tabela 1). Este comportamento pode ser explicado pelo início da senescência foliar do alho, marcada entre outros fatores, por uma elevada redistribuição de nutrientes da parte aérea para o bulbo, entre 120 e 150 dias após o plantio (Silva et al., 1970; Resende, 1997). Reforçando esta hipótese, verificou-se que aos 80 dias, época em que a parte aérea encontra-se em pleno crescimento, houve uma correlação significativa entre a altura da planta e o $\mathrm{N}$ acumulado na parte aérea.

As produções total e comercial foram significativamente $(\mathrm{p}<0,01)$ influen- 
ciadas pelo $\mathrm{N}$, apresentando relações quadráticas com as doses de $\mathrm{N}$ utilizadas (Figuras 6 e 7). Enquanto a produção comercial atingiu o ponto máximo, segundo a regressão, em 18,77 t/ha para uma dose de $194,4 \mathrm{~kg} / \mathrm{ha}$ de $\mathrm{N}$, a produção total evoluiu, ainda que com pequena intensidade, até a dose de $234 \mathrm{~kg} / \mathrm{ha}$, onde obteve-se uma produção calculada de aproximadamente 18,69 t/ha. Nota-se, portanto, praticamente nenhuma variação entre a produção total e comercial em função do baixo índice de descarte de bulbos devido, principalmente, ao pequeno número de bulbos com diâmetro inferior ao padrão comercial, em conseqüência do efeito da cultura de tecidos e à mínima ocorrência de superbrotamento em alhos do grupo semi-nobre. Respostas significativas de alho proveniente de cultura de tecidos à adubação nitrogenada foram, de forma similar, verificadas por Barni \& Garcia (1994) e Resende (1997), entretanto, trabalhando com níveis inferiores de $\mathrm{N}$, até 120 e $140 \mathrm{~kg} / \mathrm{ha}$ de $\mathrm{N}$ respectivamente. Para o alho comum ou semi-nobre multiplicado de forma convencional, as recomendações de adubação com $\mathrm{N}$ encontram-se na faixa de 60 a 100 kg/ha (Raij et al., 1996).

Pode-se concluir, portanto, que o alho proveniente de cultura de tecidos responde a doses mais elevadas de nitrogênio, tanto em termos de crescimento quanto de produção, que o alho multiplicado de forma convencional. Considerando a obtenção de produções comerciais, os níveis de resposta chegaram a aproximadamente $195 \mathrm{~kg} / \mathrm{ha}$ de $\mathrm{N}$, sendo quase duas vezes superior ao recomendado para o alho propagado pela via convencional. Para produção total de bulbos obteve-se resposta até $234 \mathrm{~kg} / \mathrm{ha}$ de N.

Outra conclusão importante referese à absorção de $\mathrm{N}$ pela planta, que acompanhou de forma proporcional o aumento dos níveis deste nutriente no solo e correlacionou-se significativamente e de forma positiva com o aumento na altura da planta, peso do bulbo, produção total e comercial.

\section{LITERATURA CITADA}

BARNI, V.; GARCIA, S. Comportamento do alho Quitéria isento do Virus do Estriado Amarelo do Alho em diferentes condições de cultivo. Hortisul, Pelotas, v. 3, n. 1, p. 15-19, jan. 1994.
Tabela 1. Correlação entre as características de crescimento e produção com a absorção de nitrogênio pelas plantas de alho provenientes de cultura de tecidos. Marília (SP), UNIMAR, 1997.

\begin{tabular}{lc}
\hline Características correlacionadas & $\begin{array}{c}\text { correlação } \\
\text { (r) }\end{array}$ \\
\hline Altura da planta (80 dias) x N absorvido pela parte aérea & 0,8435 * \\
Altura da planta (120 dias) x N absorvido pela parte aérea & $0,6567 \mathrm{~ns}$ \\
Matéria seca das folhas (120 dias) x N absorvido pela parte aérea & $0,5594 \mathrm{~ns}$ \\
Matéria seca do bulbo total (120 dias) x N absorvido pelo bulbo & 0,9743 ** \\
Peso médio do bulbo total x N absorvido pelo bulbo & 0,9515 ** \\
Peso médio do bulbo comercial x N absorvido pelo bulbo & 0,9816 ** \\
Produção total x N total absorvido pela planta & 0,9806 ** \\
Produção comercial x N total absorvido pela planta & 0,9375 ** \\
\hline$*, * *$, ns: correlações significativas aos níveis de 5 e 1\% de probabilidade e não significati- \\
va, respectivamente, pelo teste t de Student.
\end{tabular}

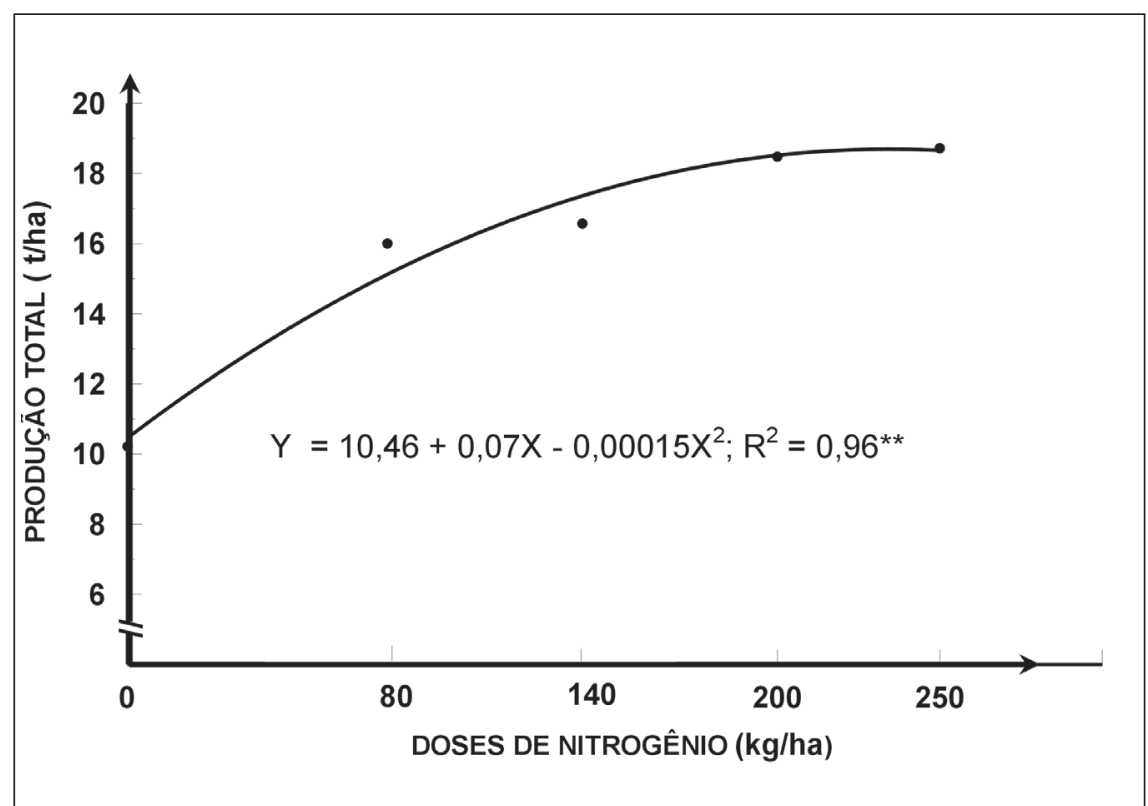

Figura 6. Produção total de plantas de alho provenientes de cultura de tecidos em função das doses de nitrogênio aplicadas. Marília (SP), UNIMAR, 1997.

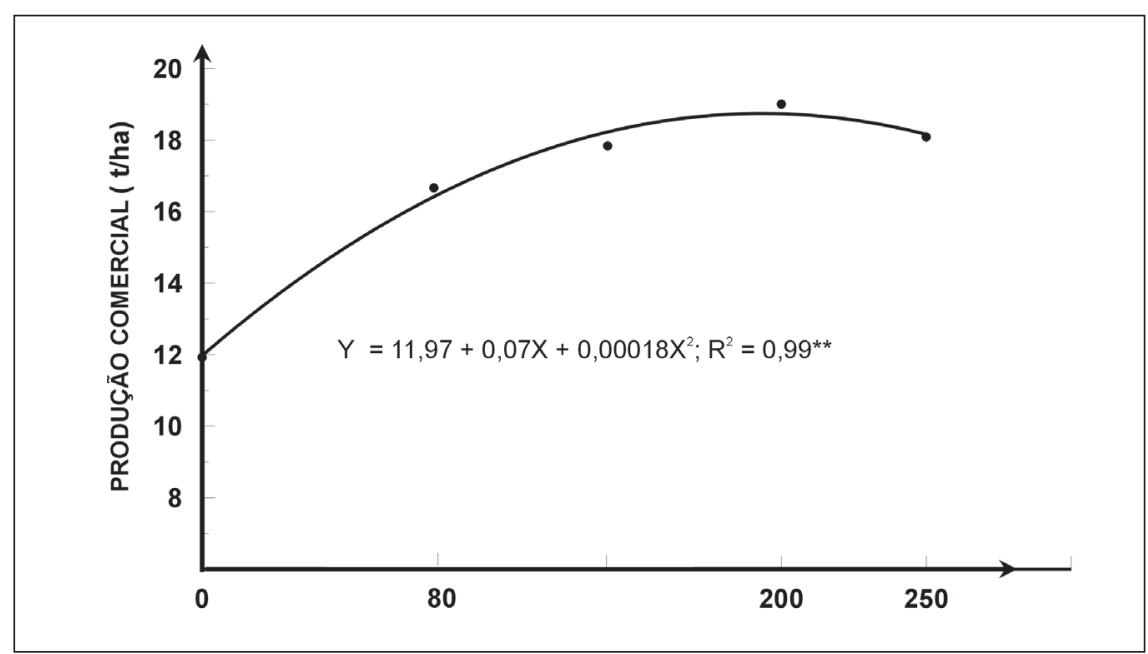

Figura 7. Produção de bulbos comerciais de plantas de alho provenientes de cultura de tecidos em função das doses de nitrogênio aplicadas. Marília (SP), UNIMAR, 1997. 
DUSI, A.N. Doenças causadas por vírus na cultura do alho. Informe agropecuário, Belo Horizonte, v. 17, n. 183, p. 19-21, 1995.

EMPRESA BRASILEIRA DE PESQUISA AGROPECUÁRIA. Cultivo do alho. Brasília: CNPH, 1984. 16 p. (Instrução Técnica n. 2).

GIBBS, A.; HARRISON, B. Plant Virology: the principles. New York: Buffer and Turner, 1979. 292 p.

GOMES, F.P. Curso de estatística experimental. Piracicaba: Nobel, 1990. 468 p.

LITTLE, T.M.; HILLS, F.J. Agricultural Experimentation, New York: John Willey and sons, 1978. $350 \mathrm{p}$

MALAVOLTA, E.; VITTI, G.C.; OLIVEIRA, S.A. de. Avaliação do estado nutricional das plantas: princípios e aplicações. Piracicaba: POTAFOS, 1989. 201 p.

MAKSOUD, M.A.; FODA, S.; TAHA, E.M Effect of different fertilizers on quality and yield of garlic. Egyptian Journal of Horticulture, v. 11, n. 1, p. 51-58, 1984.
MANN, L.K. Anatomy of the garlic bulb and factors affecting bulb development. Hilgardia, v. 21, n. 8, p. 195-251, 1952.

MENEZES SOBRINHO, J.A.; NOVAIS, R.F.; SANTOS, H.L.; SANS, L.M.A. Efeito da adubação nitrogenada, de diferentes espaçamento entre plantas e da cobertura morta do solo sobre a produção do alho. Revista Ceres, Viçosa, v. 21, n. 11, p. 458-469, 1974.

RAIJ, B.V.; CANTARELLA, H.; QUAGGIO, J.A.; FURLANI, A.M.C. Boletim técnico 100: Recomendações de adubação e calagem para o estado de São Paulo. 2 ed., Campinas: IAC, 1996. $285 \mathrm{p}$

RESENDE, F.V. Crescimento, absorção de nutrientes, resposta à adubação nitrogenada e qualidade de bulbos de alho proveniente cultura de tecidos. Lavras: UFLA, 1997, 139 p. (Tese doutorado).

RESENDE, G.M. de. Influência do nitrogênio $e$ paclobutrazol na cultura do alho (Allium sativum L.). Lavras: ESAL, 1992. 107 p. (Tese mestrado)
SANTOS, A.V.X.; LEAL, E.P.; MENDES, J.E.S. Efeito da dosagem crescente de nitrogênio mineral na cultura do alho (Allium sativum L.), em Jacobina, BA. In: CONGRESSO BRASILEIRO DE OLERICULTURA, 24., 1984, Jaboticabal. Resumos... Jaboticabal: FCAV/ UNESP, 1984. p.1.

SILVA, N. da; OLIVEIRA, G.D. de; VASCONCELOS, E.F.C.; HAAG, H.P. Absorção de nutrientes pela cultura do alho. O Solo, Piracicaba, v. 62, n. 1, p. 8-17, jun. 1970.

SOUZA, R.J. de. Influência do nitrogênio, potássio, cycocel e paclobutrazol na cultura do alho (Allium sativum L.). Viçosa: UFV, 1990. 143 p. (Tese doutorado).

ZINK, K.F.W. Rate of growth and nutrient uptake and nutrient absorption of late garlic. Proceedings of American Society of Horticultural Science, v. 83, p. 579-584, 1963. 